\title{
Service as a function of transport and an activity in the anthropotechnics management
}

\author{
Vitaly Chulkov ${ }^{1, *}$ \\ ${ }^{1}$ Moscow State University of Civil Engineering, Yaroslavskoeshosse, 26, Moscow, 129337, Russia
}

\begin{abstract}
Improvement of transport management, automation, modularity, containerization are the main directions for increasing labor productivity and reducing the duration of the transport cycle, not only due to the growth of traffic speeds, but also due to a reduction in downtime in points. At the end of the XX - beginning of the XXI century, significant changes occurred in the economies of developed countries, including Russia. Enterprises began to introduce new methods and technologies for the delivery of goods, based on the concept of integration of transport and logistics, on the development of advanced technology in the field of informatics and communications. The principles of certification of services in transport production, the specifics of transport services and their classification, logistics services, as well as the sequence and methods of system analysis in transport for service are considered.
\end{abstract}

\section{Introduction}

Studies of transport as the most important component of the Russian economy [1] and the functional philosophy of technology [2] have been known since the first years of the 21 st century. These studies cover a rather wide front of problems and directions: from complex security $[4,6,17,18,19,20$, etc.] and organizational-anthropotechnical [24, etc.] and organizational and technological reliability of functional systems "mantechnics-habitat, MTH" in the field of transport and construction [8, 9, 15, 23, etc.] to the role of science in improving the quality of life [5] and promoting innovation [14].

An important problem, the solution of which directly affects the quality of human productive activity and its vital activity, is the creation and improvement of the certification system of the country's transport complex [10], taking into account the interrelationships between the parameters of the reconfigurable systems in construction and transport [13]

The researchers pay much attention to the influence of transport and construction on the state of ecology and to finding a way out of the ecological impasse [22], considering separately the investment interaction between the subjects of the transport process in the transport sector and within the construction industry [16]. It became clear that maintenance, as a function of anthropotechnical management in transport

*Corresponding author: vitolch@gmail.com 
and in construction, is often realized in conditions of significant uncertainty [11] without using the achievements of social psychology [12].

The most common process in modern management is reorganization, and one of its stages is the reorganization of production facilities and processes based on innovations in the field of service [20]. An important role in resolving these problems should be played by regional modernization institutions [21].

The analysis of the listed and interrelated directions of carried out researches allows to consider that the issues of service considered in the article as functions of transport and as activities in the service of anthropotechnology of management are relevant and of scientific and practical interest.

\section{Materials and methods}

Beginning in the 1980s, transport began to grow together with the production that was being serviced, turning it into a link in the unified production-transport-distribution system. A new approach to transport, as a key part of the logistics chain, led to the need to consider the transport sector in various aspects. Under the conditions of the administrative command system in the country, lack of competition and market relations, most transport enterprises performed only transportation operations, not caring about providing a range of other services.

New economic conditions, the formation of the transport services market, the emergence and intensification of competition between transport enterprises imply an active study of foreign experience of the functioning of transport in countries with a market economy.

The concept of "transport service" is increasingly used in the practice of organizing and planning the work of transport. In modern notions, all types of labor include:

- are not directly related to the change and transformation of different forms of matter and phenomena of nature;

- produce a specific use value, which is the result of socially useful activity in various branches of public management.

The services include those types of labor that are not embodied in a tangible, separate product of labor (for example, transport, communications). The specific features of the service provision activity are reduced to the following provisions:

- services can not exist outside the process of providing them (ie, they can not be "accumulated");

- sale of services is actually the sale of the labor process itself, therefore the quality of the service is determined by the quality of the labor process;

- services represent a specific use value only at a specific time, in a particular place or in a specific direction (that is, "here and now"), which significantly limits the possibility of their alternative replacement in the services market;

- transport services are referred to services that precede and / or terminate the process of material production.

\section{Results}

The transport service is a subset of the transport activity aimed at meeting the needs of people and characterized by the availability of the necessary technological, economic, information, legal and material resources. 
Transport service implies not only the actual transportation of goods or passengers. This is any operation that is not part of the transportation process but is related to its preparation and implementation.

The transport services include:

- transportation of cargo and passengers;

- loading and unloading operations (loading, unloading, reloading, passenger transfer, intra-warehouse operations);

- storage of goods;

- preparation of conveyances;

- provision of conveyances on a rental (hire) basis;

- transportation (delivery) of new and repaired vehicles;

- other transport services.

As a result of the analysis of foreign and domestic experience, the following classification of transport services is proposed:

- on the basis of the relationship with the main activity of transport enterprises:

- transportation (including in some form of the element of transportation);

- not shipment;

- according to the type of consumer to whom the service is provided:

- external (provision of services to non-transport enterprises and organizations);

- internal (provision of services to other transport enterprises and organizations); For example, internal is the service for the provision of rolling stock by a road transport forwarding company for the performance of transport operations;

- by the nature of the activity associated with the provision of a certain service:

- technological;

- commercial;

- information;

- other services

An important type of services that have arisen and are actively developed in the transport sector in the period of globalization are logistics.

Arising as an element of provision in the military sphere, logistical activity eventually became an organic component of many civilian areas of management, including transport.

Being essentially a service, logistic activity has become an integral part of service in the transport sector.

Logistic (including transportation) services are based on the following provisions and rules:

- each service is unique to the recipient;

- in the end, nothing is left from the rendered service, except for the perception of information about its timeliness and quality;

- the service (or part of it) can not be recycled (reworked or modified for use in the same place);

- services can not be earned "in reserve";

- the service can not be "repaired";

- the service rendered can not be performed again (this will be another service);

- the memory of a good service is fleeting, a bad service is remembered for a long time.

The importance and significance of logistics services is constantly growing, the industry of such services is constantly expanding. Logistics intermediaries are becoming service companies, which services are inextricably linked with the 
promotion and sale of goods, with the cost of services may exceed the direct costs of production.

Widely used effective quantitative methods for assessing the quality of services are not due to their characteristics:

- intangibility of services;

- the consumer of the service often participates in the process of rendering it;

- the consumer of services does not become their owner;

- the provision of services is a process and it can not be tested before payment;

- service delivery process can be a sequence of local operations, each of which contributes to the total quality and cost of services, while important today only the final assessment.

The importance and significance of logistics services is constantly growing, the industry of such services is constantly expanding. Logistics intermediaries are becoming service companies, which services are inextricably linked with the promotion and sale of goods, with the cost of services may exceed the direct costs of production.

Widely used effective quantitative methods for assessing the quality of services are not due to their characteristics:

- intangibility of services;

- the consumer of the service often participates in the process of rendering it;

- the consumer of services does not become their owner;

- the provision of services is a process and it can not be tested before payment;

- service delivery process can be a sequence of local operations, each of which contributes to the total quality and cost of services, while important today only the final assessment.

The most important components in assessing the quality of services provided can be:

- environment (interior, equipment, appearance of staff, etc.);

- reliability (execution on time);

- responsibility (guarantees of the performance of services, the desire of staff to help the consumer of services);

- completeness (availability of necessary skills and knowledge, competence of personnel);

- availability (ease of establishing contacts);

- safety (absence of risk and mistrust from the consumer of services);

- courtesy (courtesy, correctness of staff);

- communicability (the ability of personnel to communicate with the consumer of services in an accessible and understandable language);

- mutual understanding (sincere interest in the consumer services, the ability to understand and evaluate his position).

The consumer evaluates the quality of services by comparing the actual quality parameters of the service with the expected ones.

If they are close, then the consumer considers the service to be satisfactory (acceptable).

Criteria for the evaluation of the customer-consumer services arise as a result of the following circumstances:

- voice communication (opinions and "rumors") - information about the services that consumers of services transmit to each other;

- personal needs (customer's presentation of quality, his requests);

- past experience (similar services provided to the client in the past); 
- External communications (messages received through the media: radio, television, press).

In connection with the introduction of logistics in countries with a market economy, they revise the transport policy, which begins to play a key role in the system of commodity circulation.

In the future, the technical and operational features of certain modes of transport will ensure them a reliable position in the transport services market, especially in conditions of increased demand for the transport of goods by small shipments. This, in turn, accelerates the development of automated cargo handling, containerization and packaging, as well as computer science in the field of freight and transportation activities in the transport sector.

There are two directions in the organization of transport services:

- adaptation of the range of services offered to specific customer requirements;

- active formation of demand for available transport services for the purpose of their profitable realization.

The study of demand for transportation services shows that one of the main requirements of customers for the work of transport is the timeliness of sending and delivering goods. This is due to the desire of most cargo owners to reduce inventories in the spheres of production and circulation. Statistics show that the cost of maintaining stocks account for more than $20 \%$ of the value of manufactured products in a number of industries.

The lack of a guarantee of timely delivery or dispatch of the required cargo, the possibility of refusal or repeated postponement of an application for transportation were and often remain features of the existing system of transport operations.

Delivery of products - a set of consistently performed often not connected between different organizations or their departments of individual stages. Optimizing such a "chain" in market conditions is quite a difficult task.

Transport service and its nature largely determines the demand for transportation, taking into account the following parameters:

- type of cargo (type of trip) and volume of traffic;

- the size of the territory served;

- regularity of cargo flows (passenger flows);

- urgency and time of delivery;

- level of tariffs;

- the need to store goods (technological downtime-transplant) in the delivery cycle;

- legal position of the sender or recipient (company or individual).

Demand is local in nature and its purchasing power, which exists in this particular region, affects its quantitative and qualitative characteristics, since, depending on it, demand changes. The proposal is dispersed and varies quantitatively and qualitatively, depending on the availability or lack of opportunities for making a profit (or meeting the needs) in the local market.

Countries with developed market economies demonstrate the following trends in the development of transport services:

- increase in the volume of transportation of high-value cargo with simultaneous reduction of low-value cargo (or non-urgent passenger movements);

- Increase in average delivery distances and increase in the share of international traffic;

- Increase of responsibility for quality and terms of transportation throughout the transport chain; 
- Increase in the volume of transport between enterprises with a reduction in the volume of transport in the enterprises themselves;

- reduction in the volume of bulk bulk cargo and increase in the volume of piece cargo in containers and pallets;

- increase in the load-carrying capacity of the rolling stock (passenger capacity);

- increase in the volume of cargo (passenger) transportation in a specialized rolling stock;

- the prevalence of logistics approaches in the organization of transportation and the management of the transport process.

Qualitative customer service (service) is characterized by two aspects:

- this is an important part of marketing, a powerful tool of the firm in the struggle for the sales market;

- is an element of the technological process (delivery "just in time").

Services at transport terminals and in logistics centers are conventionally divided into:

- overload services;

- service of cargo spaces (rent, warehousing);

- maintenance of vehicles (rent, parking, maintenance, washing);

- network maintenance (initial and final operations, customs services, traffic control system);

- services related to the cargo (loading, unloading, provision of warehouses).

The proposition that the provision of quality services is very expensive pleasure

is erroneous. On the contrary, failure to comply with the terms of the adopted agreement entails additional expenditures of material and labor resources for the elimination of errors, and systematic disruptions in the transportation schedule lead ultimately to loss of customers, reputation and place in the transport services market.

Requirements for transport services are identified by the principle of segmentation of services (group consumers according to a certain criterion of service).

The segmentation of services is divided into stages:

- identify the key components of service based on the opinions of consumers;

- establish the relative importance of these components to consumers;

- group consumers in relation to the preferences of specific service components.

The information is collected by the survey method, processing it and grouping consumers by statistical methods.

Key parameters of transport service quality:

- time from receipt of the order for transportation to delivery;

- reliability and availability on demand;

- availability of stocks, stability of supply;

- completeness and degree of availability of the order;

- convenience of placement and order confirmation;

- the objectivity of tariffs and the regularity of information on the costs of services;

- possibility of granting loans;

- efficiency of cargo handling in warehouses;

- quality of packaging, as well as the ability to perform package and container transportation.

Depending on the interests and inclinations of consumers, they are divided into three groups:

- prefer high quality of service;

- focus on high speed, efficiency and minimum risk; 
- delegate the maintenance of the processes of transportation, sales and sale of products to intermediaries.

- The basic method of studying service and service in the activity of anthropotechnical management is system analysis, among which:

- decomposition (representation of activity as a set of operations, each of which can be divided into "system-quanta");

- analysis (finding various kinds of activity properties, making up its operations and their systemquants, as well as the habitat of the person with the purpose to determine the patterns of performance of the activity and behavior of the person in the process of performing the activity);

- synthesis (based on knowledge of the activities and activities received in the first two tasks, the creation of a model of activity and behavior in it, the definition of the structure of their interaction, the parameters that ensure the effective functioning or development of activities and leading to the goal).

\section{Discussion}

The main functions of system analysis within these three main tasks are presented in Table 1.

Table 1. Structure of the system analysis.

\begin{tabular}{|c|c|c|}
\hline \multicolumn{3}{|c|}{ Structure of the system analysis } \\
\hline Decomposition & Analysis & Synthesis \\
\hline $\begin{array}{l}\text { Definition and } \\
\text { decomposition of a } \\
\text { common goal, the main } \\
\text { function }\end{array}$ & Functional-structural analysis & $\begin{array}{l}\text { Development of the system } \\
\text { model }\end{array}$ \\
\hline $\begin{array}{l}\text { Isolating the system from } \\
\text { the environment }\end{array}$ & $\begin{array}{l}\text { Morphological analysis } \\
\text { (analysis of the relationship of } \\
\text { components) }\end{array}$ & Structural synthesis \\
\hline $\begin{array}{l}\text { Description of the impact } \\
\text { factors }\end{array}$ & $\begin{array}{l}\text { Genetic analysis (analysis of } \\
\text { prehistory, trends, forecasting) }\end{array}$ & Parametric synthesis \\
\hline $\begin{array}{l}\text { Description of } \\
\text { development trends, } \\
\text { uncertainties }\end{array}$ & Analysis of analogues & Evaluation of the system \\
\hline $\begin{array}{l}\text { Description as a "black } \\
\text { box" }\end{array}$ & Efficiency analysis & \\
\hline $\begin{array}{l}\text { Functional, component and } \\
\text { structural decomposition }\end{array}$ & $\begin{array}{l}\text { Forming requirements for the } \\
\text { system being created }\end{array}$ & \\
\hline
\end{tabular}

The central procedure of system analysis is the construction of a generalized model that reflects the factors and relationships of the real situation that manifest themselves in the implementation of the solution. The model is examined to find out the proximity of the result of an alternative variant of the action to the desired, comparative expenditure of resources for each of the options and the degree of sensitivity of the model to various undesirable external influences (table 2).

In the transport sector, due to its complexity and scale, carrying out experimental studies is either very expensive, or even impossible. Therefore, either combined studies are used (when only separate elements of transport systems are subjected to field tests), or they have to be limited to computational experiments, which determines the importance of system engineering modeling in the study of transport systems and the activities carried out in them. 
Systems analyst is considered a technical application of the system approach to complex human-machine systems, which determined the object of system engineering - systemtechnical complexes (STC).

The peculiarity of STK is a significant heterogeneity (technical components and people: managers and personnel).

The subject of system engineering is the provision of a complete "life cycle" of systems (design, testing, production, operation and liquidation). The main attention is paid to the design of systems, which includes the methodology of searching for the system characteristics of the STC and the methods of forming an effective system of design procedures.

When designing complex systems, five stages are distinguished:

- preliminary research;

- creating a system model;

- study of the proposed model;

- actual design;

- prototype construction.

There are no clear boundaries between the stages, designers can revert back to any stage of development (the principle of sequential-parallel solution of the problem).

Table 2. Stages and results of system analysis.

\begin{tabular}{|c|l|l|}
\hline $\begin{array}{c}\text { Sequence } \\
\text { number of } \\
\text { the stage }\end{array}$ & \multicolumn{1}{|c|}{ Name of the stage } & \multicolumn{1}{c|}{ The result of the stage } \\
\hline 1 & System specification & $\begin{array}{l}\text { Determination of the boundary with the } \\
\text { environment, variables, purpose of } \\
\text { functioning }\end{array}$ \\
\hline 2 & $\begin{array}{l}\text { Structuring knowledge about } \\
\text { the system }\end{array}$ & Determining the functional dependencies \\
\hline 3 & Nomination of the hypothesis & $\begin{array}{l}\text { Determination of the verification } \\
\text { procedure }\end{array}$ \\
\hline 4 & $\begin{array}{l}\text { Formalization of knowledge } \\
\text { about the system }\end{array}$ & $\begin{array}{l}\text { Algorithmization of the processes of the } \\
\text { system }\end{array}$ \\
\hline 5 & System identification & System model development \\
\hline 6 & Experimental studies & Verification of the model \\
\hline 7 & Interpretation of the experiment & Acquisition of new knowledge \\
\hline
\end{tabular}

The peculiarity of STC is a significant heterogeneity (technical components and people: managers and personnel).

The subject of system engineering is the provision of a complete "life cycle" of systems (design, testing, production, operation and liquidation). The main attention is paid to the design of systems, which includes the methodology of searching for the system characteristics of the STC and the methods of forming an effective system of design procedures.

When designing complex systems, five stages are distinguished:

- preliminary research;

- creating a system model;

- study of the proposed model;

- actual design;

- prototype construction.

There are no clear boundaries between the stages, designers can revert back to any stage of development (the principle of sequential-parallel solution of the problem). 
On the Fig.1 the general structure of the STC is shown, the individual systems of which include technical components and the personnel interacting with them, carrying out the functional activities, developing it and changing it as appropriate.

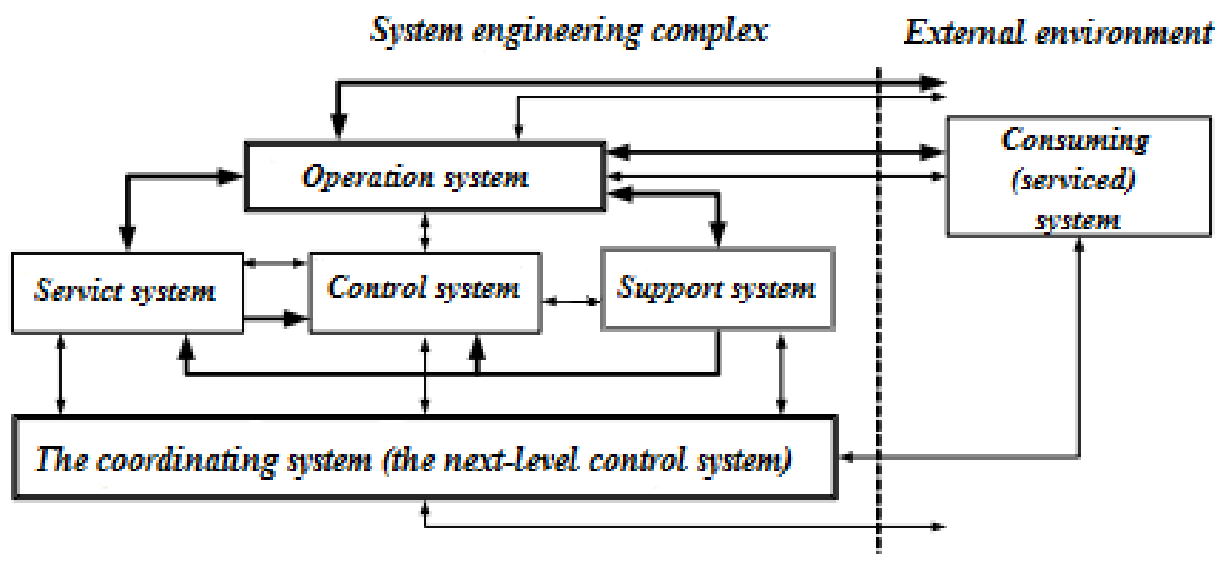

Fig. 1. Basic structure of STC.

At the stage of preliminary research, study the boundary conditions of the problem, set the desired characteristics of the subsystems, determine the economic aspects of the project. Precisely formulate the purpose of the system and the basic requirements for it. They study similar systems, including the influence of external conditions and interference on them. Assess the compatibility of the system with environmental conditions and economic requirements.

In the second and third stages, a model of the system is created, its computer simulation is carried out, the possibilities of interaction of subsystems and the influence of various parameters on the system's efficiency are evaluated.

In the last two stages, the development is completed using a wide range of scientific and technical knowledge and means. After the completion of the design, a prototype (prototype) of the system is built.

If the prototype tests are successful, they conclude that the development is complete.

The stages of system development are divided into two levels:

- macro-design ("external" design), where they solve common functional and structural problems of the system as a whole; Begin with the formulation of the problem, which includes at least three main sections: - Defining the goals of creating a system and the range of tasks it solves; - evaluation of factors affecting the system and determining their characteristics; - choice of system performance indicators;

- micro-design ("internal" design), associated with the physical embodiment of the elements of the system.

\section{Conclusions}

1. The goals and objectives of the system are determined on the basis of the need for their practical use, taking into account the trends and features of scientific and technological progress, as well as economic feasibility. The experience of using similar systems is important and a clear understanding of the role of the projected system in the business process of the organization.

To evaluate the external and internal factors acting on the system, in addition to the experience of operating similar systems, statistical data obtained as a result of experimental 
studies are used. The results of the conducted experiments are used to justify the technical task for the system development, and the performance indicators are chosen by numerical estimates of the degree of the system's compliance with the tasks assigned to it. We have to compromise between the requirements for different subsystems and their characteristics. Careful research and modeling of parts of the system in their interconnection often allows us to identify ways to optimize and simplify the system as a whole.

Usually this leads to a system that is more efficient, cheaper and more reliable than a system designed without such an approach.

2. The basis of the STC is the operating (production) system, which, in accordance with its purpose, ensures the solution of the necessary range of technological tasks for the production of a certain product or service. The operating system includes technical means for the implementation of technological operations, as well as information, energy, materials and personnel. The leading role is played by a management system that supports the necessary level of organization of all processes in the STC. The servicing system minimizes the rate of loss of operability of the technical components of the system, and if it becomes unusable, it restores it to the maximum possible extent within the time no more permissible.

3. The security system creates the necessary conditions for implementing the procedures for using the system. Information-energy connections (thin lines) and real connections (thick lines) in Fig. 2 together form a subsystem of communication, the main task of which is to move the elements in the space between the communicating components of the STC.

4. Diagnostics, registration, monitoring and analysis of the functioning of these systems, the formation of targets and the provision of external relations are the main tasks of the coordinating system, which, in essence, is the control system of the next hierarchical level and represents the highest level of management (top management).

5. The consuming system is one of the subsystems of the external environment. Its selection in Fig. It is advisable, since it is most closely connected with the STK, it has a determining influence on it and usually the sense of functioning of the STC is reduced to meeting the requirements of the consuming system.

\section{References}

1. N.V. Akindinova, Ya.I. Kuzminov, E.G. Yasin, Voprosy ekonomiki, 6 (2016)

2. N.M. Al-Ani, Philosophy of Technology: Essays on History and Theory (Proc. Allowance, SPb, 2004)

3. A.Ya. Antsupov, A.I. Shipilov, Conflictology (Peter, St. Petersburg, 2015)

4. Life safety. Organizational-anthropotechnical reliability of functional systems of the mobile environment of building production (ASV, Moscow, 2003)

5. S.S. Bityukov, The role of science in improving the quality of life, Articles on the materials of the II International Forum "Quality of Life: Commonwealth of Science, Power, Business and Society" (2005)

6. S.V. Bolgov, Automated design of buildings with a specified level of operational safety during the operational phase (TSNIIOMTP, Moscow, 2004)

7. A fairly general theory of management is sufficient (Conceptual, Moscow, 2012)

8. K. Sudakova, Infographies of functional systems (The New Millennium Foundation, Moscow, 2004)

9. V.O. Chulkov, P.D. Burianov, Mechanization of construction 11, 24-25 (2003)

10. R.R. Kazaryan, V.O. Chulkov, Organizational and technological innovations of housing and communal and investment-building complexes in the development of the city: International collection of scientific papers (MGAKHiS, Moscow, 2012) 
11. E.V. Kaznacheeva, Management in conditions of uncertainty (Higher School of Economics, Moscow, 2014)

12. Yu.L. Kachanov, Epistemology of Social Science (Aleteyya, SPb, 2007)

13. V.O. Chulkov, M.S. Kiselev, Vestnik MGSU, 3 (2007)

14. N.M. Komarov, V.O. Chulkov, Innovations in the service: the use of infographics. Textbook (SOLON-PRESS, Moscow, 2014)

15. V.O. Chulkov, P.D. Buryanov, V.V. Shmakov, Industrial and civil construction, 10 (2005)

16. B.A. Lyovin, E.A. Mamaev, The World of Transport, 1 (2005)

17. B.A. Lyovin, The World of Transport, 1 (2012)

18. B.A. Levin, V.M. Ponomarev, V.A. Ulyanov, Business Premier, 1-2 (2014)

19. A.N. Lieberman, Technogenic security: the human factor (New Century, St. Petersburg, 2006)

20. Reconstruction. Organizational and anthropotechnical reliability of construction (SvR ARGUS, Moscow, 2005)

21. V.M. Polterovich, Economic Science of Modern Russia, 4 (2011)

22. A.I. Subetto, Theoretical economics, 6 (2015)

23. V.O. Chulkov, Organizational and anthropotechnical reliability of functional systems of the mobile environment (MGSU, Moscow, 2010)

24. K.V. Sudakov, V.O. Chulcov, R.R. Kazaryan, O.S. Glazachev, N.V. Dmitrieva, N.M. Komarov, Antropotechnics: Norm in every living thing and artificial beings (SvRARGUS, Moscow, 2013) 